\title{
Mechanical and Thermal Characterisation of Millscale Modified Al-Cu Alloy for Artificial Intelligence Systems
}

\author{
Olatunde Israel Sekunowo ${ }^{a}$, Catherine U. Kuforiji ${ }^{b}$, Emmanuel Oluwaseun Ajibodu ${ }^{c}$ \\ ${ }^{a, b}$ Department of Metallurgical and Materials Engineering, University of Lagos, Nigeria \\ ${ }^{c}$ Department of Mechanical Engineering, University of Ottawa, Canada \\ Corresponding Author: ${ }^{\text {a }}$ osekunowo@unilag.edu.ng
}

Received: 2020-12-07

Revised: 2021-03-20

Accepted: 2021-03-29

\begin{abstract}
:
Continuous research into critical functional property enhancement of materials employed in artificial intelligence systems is imperative to overcome performance limitations. This study investigated the thermal and mechanical properties of stir-cast fabricated Al-Cu alloy modified with addition of iron-millscale (IMS) particles varied from 2-6 wt.\%. The alloys microstructure was analysed using both optical and scanning electron microscope coupled with energy dispersive spectroscopy (SEM/EDS). PerkinEImer Thermogravimetry/Derivative thermal analyser was used to assess the alloys thermal characteristics while the mechanical properties were evaluated using relevant state of the art equipment. Results show that the best thermal and mechanical properties comparable to established standards were achieved at 6 wt.\% IMS particle addition. Contributions to the alloy enhanced performances stemmed from the structure refining propensity of IMS particles. Based on the thermal and mechanical properties demonstrated, the alloy is recommended for application in pneumatic offshore valve actuator used in oil and gas flow process lines.
\end{abstract}

Keywords: Artificial intelligence, aluminium-copper alloy, iron-millscale, mechanical properties, thermal stability

\section{Introduction}

Artificial intelligence (AI) has caused a revolution in every facet of human engagements including medical, robotics, aerospace and information technology. This has given rise to a quantum leap in the scope of artificial intelligence systems (AIS) applications [18, 26]. Thus, material selection and development has become a critical consideration for efficient performances of AIS. Among these considerations are the cost and thermal/mechanical properties in relation to the service environment. Although some of the properties exhibited by aluminum and its alloys make them a versatile and economical metallic material for a broad range of AIS applications, however the main drawback has been their thermal instability at temperatures around $200^{\circ} \mathrm{C}$ and above [5]. The structural instability of AIS at relatively elevated temperatures often results in low efficiency in service for several smart materials like shape memory alloys (SMEs); industrial robot, power-train and actuators [6, $2,3]$.
It is reported that the thermal characteristics of aluminum can be enhanced by alloying with transition elements such as nickel, chromium, iron or manganese $[16,2,3]$. This is because these elements exhibit low diffusivity and solubility in aluminum hence; they stabilize the structure at elevated temperatures resulting in desirable mechanical properties. In addition, the structures developed are capable of withstanding a wide range of high temperatures during operation [3]. In the case of iron $(\mathrm{Fe})$ addition, the mechanism of structure modification involves inducement of face-centered-cubic (FCC) phase which promotes improved thermal stability. According to Eissa et al [10]; Guan and Tie [11], Fe is an effective and efficient grain refiner in aluminum alloy systems, which enables the inducement of a hard-reinforcing phase; $\mathrm{CuAl10Fe3.} \mathrm{Structure} \mathrm{modification} \mathrm{on} \mathrm{addition} \mathrm{of} \mathrm{Fe}$ affects both the size and morphology of phases induced. Furthermore, different stable alpha (alpha) and beta $(\beta)$ phases with intermetallic precipitates of $\mathrm{Al} 3 \mathrm{Fe}$, $\mathrm{A} 15 \mathrm{Fe} 2$, and $\mathrm{Al13Fe} 4$ are known to be induced. However, the fractions of these precipitates induced 
depend on both the quantity of $\mathrm{Fe}$ in the system and other processing conditions. Nwaeju et al [19] reported similar effects on the addition of $1 \mathrm{wt} . \%$ niobium which also compared with the addition of zirconium and titanium up to $2.5 \mathrm{wt} . \%$ [17].

Granulated iron oxide, commonly called iron mill-scale (IMS) is usually formed on the surface of hot-rolled profiles such as plates, sheets, bars. IMS formation invariably represents a significant level of yield loss to steel millers as it often reflects in vast differences between input stock and final output tonnages [8, 20]. The accumulation of IMS on the shop floor over time usually create handling and disposal challenges [23]. Considering the volume and quantity produced, the quest in finding an economical way to reprocess and utilize accumulated IMS is imperative. The aim of this study is to recondition IMS as a structure modifier in $\mathrm{Al}-\mathrm{Cu}$ alloy system with a view to enhance its thermal and mechanical properties suitable for applications in artificial intelligence systems.

\section{Materials and methods}

\subsection{Materials preparation}

The materials used for this study include aluminium ingot supplied by Nigerian Aluminium Extrusion Company (NIGALEX) Lagos, Nigeria (Figure 1a), iron-millscale (Figure 1b) obtained from African Foundries, Lagos, Nigeria and copper strands (Figure 1c) sourced commercially. For ease of formulation, the aluminium ingots were preheated to $400^{\circ} \mathrm{C}$ then briquetted while copper strands were mechanically cut into sizeable bits for easy of charging into the furnace. However, the iron- millscale (IMS) was ground and sieved to remove tramps and other hard lumps to obtain a smooth (homogenous) stream of particles. Further sieving of the IMS was carried out using standard BSS sieves to obtain $150 \mu \mathrm{m}$ particle sizes. The detailed materials formulation is presented in Table 1.

Table 1: Materials formulation

\begin{tabular}{cccc}
\hline \multirow{2}{*}{ Sample ID } & \multicolumn{3}{c}{ MATERIALS, wt. \% } \\
\cline { 2 - 4 } & Aluminium & Copper & Iron-millscale \\
\hline A0 & 35 & 65 & 0 \\
\hline A2 & 35 & 63 & 2 \\
\hline A4 & 35 & 61 & 4 \\
\hline A6 & 35 & 59 & 6 \\
\hline
\end{tabular}

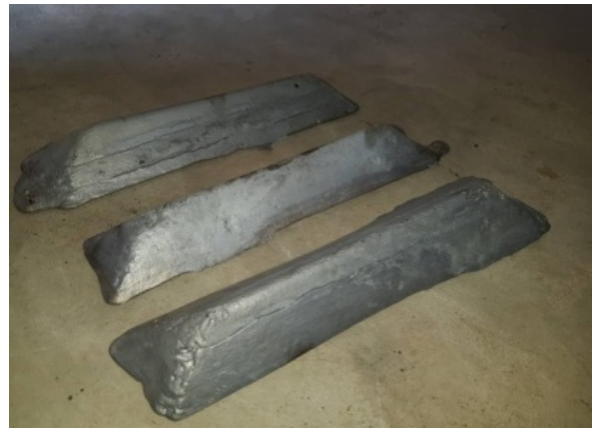

(a) Aluminium ingot

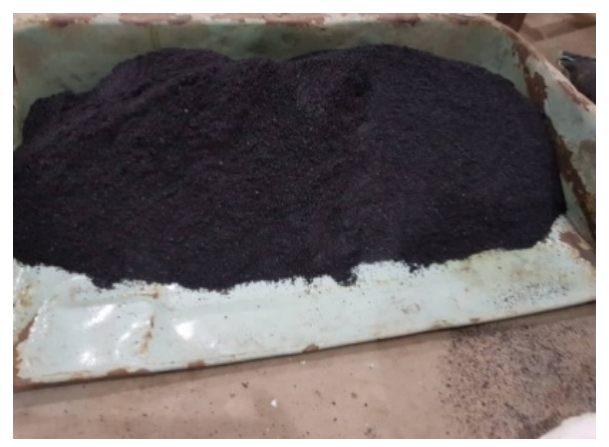

(b) IMS, $150 \mu \mathrm{m}$

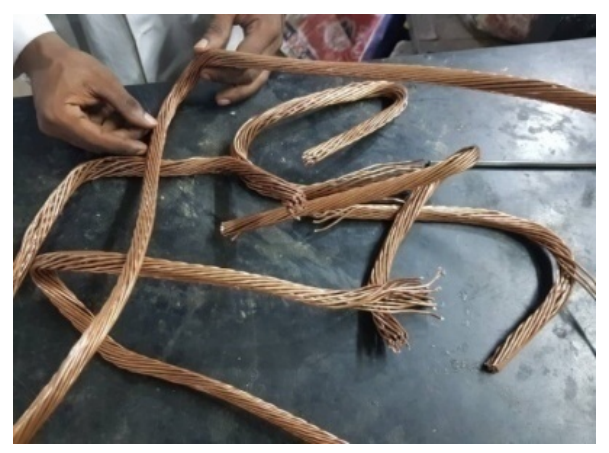

(c) Copper strands

Figure 1: Research materials

\subsection{Melting and casting}

A two-step mixing method of stir casting procedure was adopted in the development of the alloy. This entails that sized pieces of the copper strands were first charged into a crucible furnace and heated to $800^{\circ} \mathrm{C}$. Then, measured mixtures of IMS particles and aluminium briquettes were added to the molten copper according to the formulation in Table 1.

The bath was stirred thoroughly using a long stainless-steel tong followed by homogenization of the melt at $1100^{\circ} \mathrm{C}$ for $10 \mathrm{~min}$ and then poured into prepared metal moulds having four (4) sample slots per mould (Figure 2a/b). 


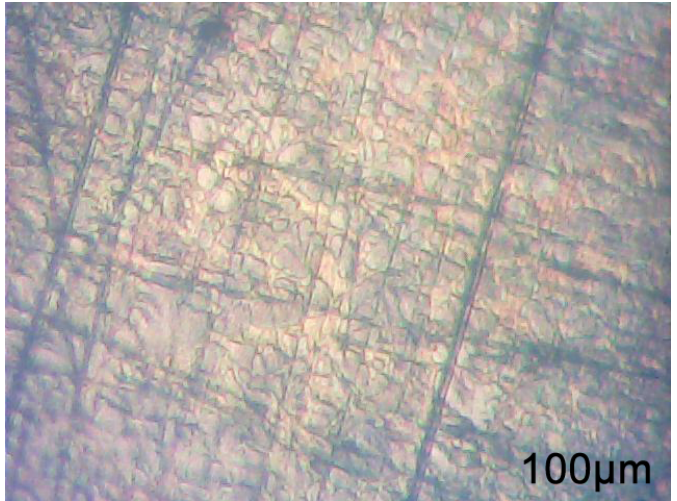

(a)

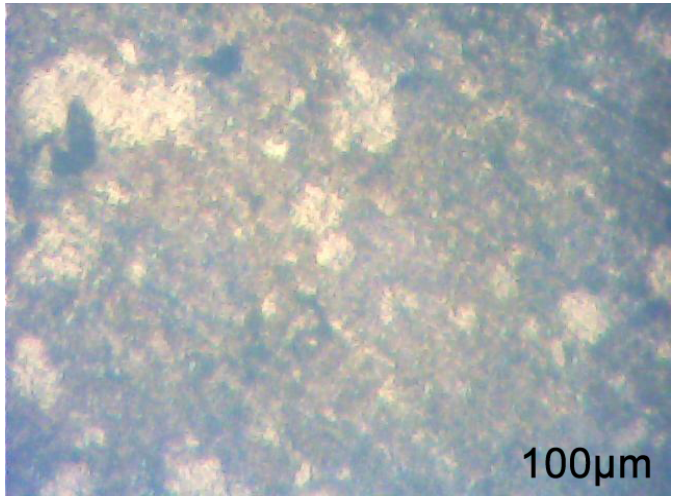

(b)

Figure 2: Pictures of (a) metal sample mould and (b) as-cast five samples per formulation

\subsection{Characterisations}

Prior to properties evaluation, the as-cast samples were annealed at $300^{\circ} \mathrm{C}$ for $2 \mathrm{hr}$ in a muffle furnace to relief inherent stress. This was followed by preparation of specimens for tensile, hardness, and impact energy (Charpy V) tests. Three specimens from each formulation were machined on a lathe machine for the tests according to ASTM B108 and ASTM E384 standards respectively. The microstructural analysis was performed using both optical and scanning electron microscopy coupled with energy dispersive spectroscopy (SEM/EDS). Thermogravimetry, PerkinElmer 4000 analyser, along with its derivative thermo-gravimetric (DTG) tool was employed to determine the alloys thermal characteristics.

\section{Results and Discussion}

\subsection{Microstructure}

The control specimen in Figure 3a shows a monolithic $\mathrm{Al}-\mathrm{Cu}$ mixture which is devoid of IMS addition.
However, on addition of 2 wt.\% IMS, few fraction of stringer-like particles known to be kappa precipitates of $\mathrm{AlCuFe}_{3}$ as reported by Pisarek [21] were seen induced within the matrix (Figure 3b). At 4 wt.\% IMS addition, the stringer-like particles have transformed into fibre-like particles with sharp protrusions (Figure 3c). According to Callister [4]; Taylor and Knott [24], such protrusions on the fibre-like particles often act as points of stress concentration in the matrix with the potential to cause mechanical properties impairment. The induced precipitates morphology on addition of $6 \mathrm{wt} . \%$ IMS further changed into fine particles and the protrusions were observed to have dissolved (Figure 3d). Owing to the promising and desirable microstructural features developed in the $6 \mathrm{wt} \%$ specimen, its microstructure was further analysed using SEM (Figure 4a) and EDS (Figure 4b). The structure displayed homogeneously dispersed fine kappa precipitates with strongly preferred orientation. This microstructure has the potential for improved mechanical and thermal characteristics $[4,7,12]$.

Table 2: Composition of IMS modified Al-Cu alloy using EDS

\begin{tabular}{|c|c|c|c|c|}
\hline $\begin{array}{c}\text { Element } \\
\text { Number }\end{array}$ & $\begin{array}{c}\text { Element } \\
\text { Symbol }\end{array}$ & $\begin{array}{c}\text { Element } \\
\text { Name }\end{array}$ & $\begin{array}{c}\text { Atomic } \\
\text { Conc. }\end{array}$ & $\begin{array}{c}\text { Weight } \\
\text { Conc. }\end{array}$ \\
\hline 29 & $\mathrm{Cu}$ & Copper & 72.54 & 82.05 \\
\hline 13 & $\mathrm{Al}$ & Aluminium & 14.70 & 7.06 \\
\hline 50 & $\mathrm{Sn}$ & Tin & 1.28 & 2.70 \\
\hline 47 & $\mathrm{Ag}$ & Silver & 1.11 & 2.14 \\
\hline 14 & $\mathrm{Si}$ & Silicon & 2.63 & 1.32 \\
\hline 19 & $\mathrm{~K}$ & Potassium & 1.23 & 0.86 \\
\hline 11 & $\mathrm{Na}$ & Sodium & 1.96 & 0.80 \\
\hline 22 & $\mathrm{Ti}$ & Titanium & 0.85 & 0.72 \\
\hline 16 & $\mathrm{~S}$ & Sulfur & 1.09 & 0.62 \\
\hline 15 & $\mathrm{P}$ & Phosphorus & 1.08 & 0.60 \\
\hline 26 & $\mathrm{Fe}$ & Iron & 0.36 & 0.36 \\
\hline 20 & $\mathrm{Ca}$ & Calcium & 0.41 & 0.29 \\
\hline 25 & $\mathrm{Mn}$ & Manganese & 0.29 & 0.28 \\
\hline 12 & $\mathrm{Mg}$ & Magnesium & 0.46 & 0.20 \\
\hline
\end{tabular}

\subsection{Thermal stability}

The alloy thermal stability threshold was measured using Thermogravimetry/Derivative Thermogravimetry (TG/DTG) analytical tool. The test was conducted using $12.93 \mathrm{mg}$ of both the control and $6 \mathrm{wt} . \%$ IMS samples. Figures $5 \mathrm{a}$ and $5 \mathrm{~b}$ show the plot of the TG curve (red colour) superimposed on the DTG curve (blue colour). The TG curve displaced from left to right indicate an onset of $92.5 \%$ weight-loss at $250^{\circ} \mathrm{C}$ and 


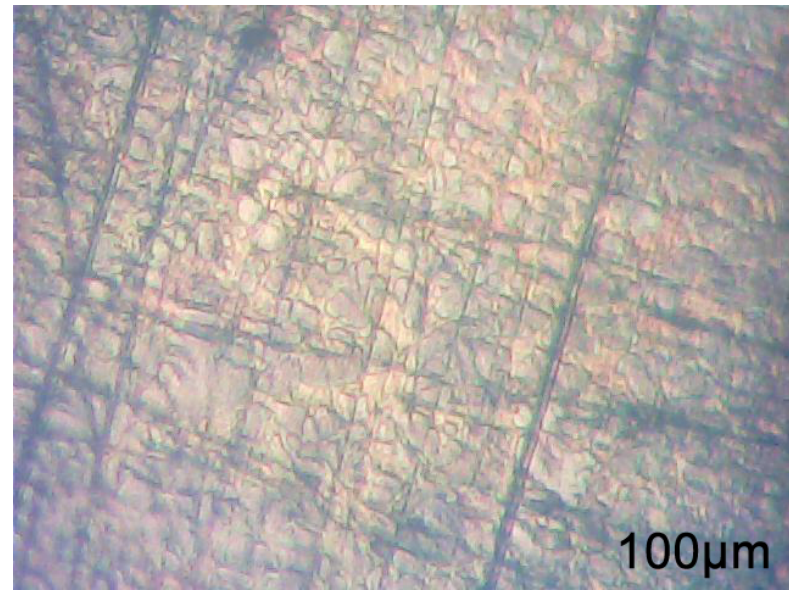

(a) 0 wt. $\%$

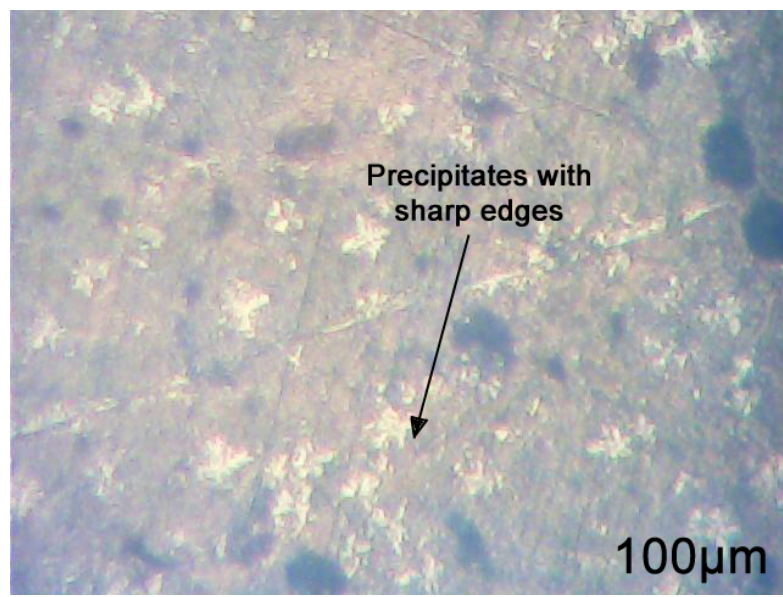

(c) $4 \mathrm{wt} . \%$

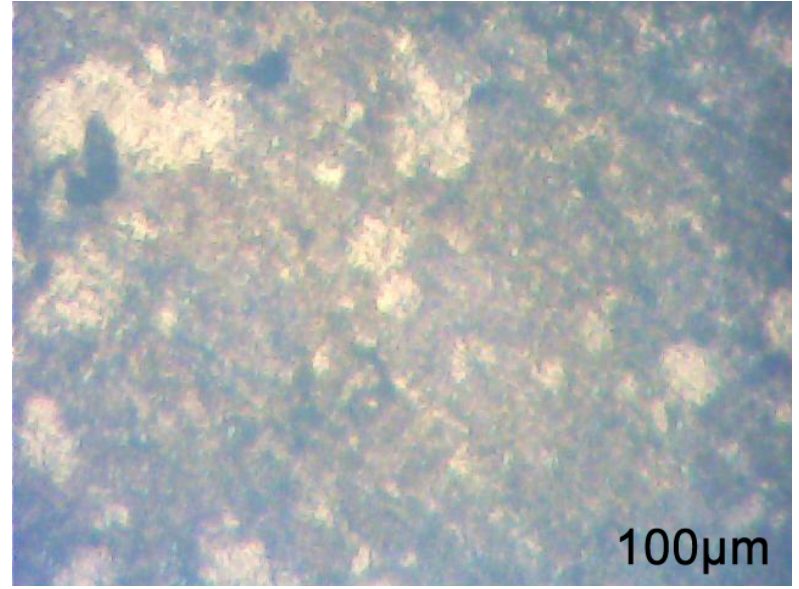

(b) 2 wt. $\%$

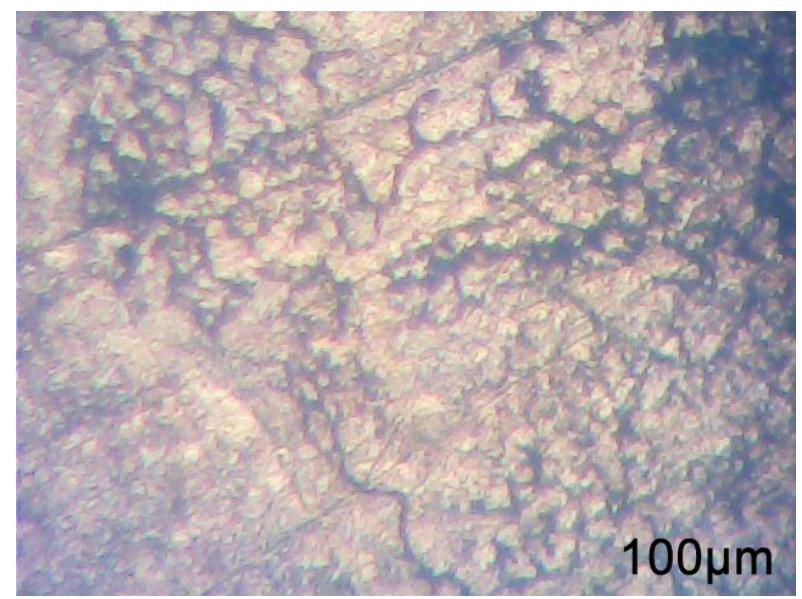

(d) $6 \mathrm{wt} . \%$

Figure 3: Optical micrographs at varied IMS addition

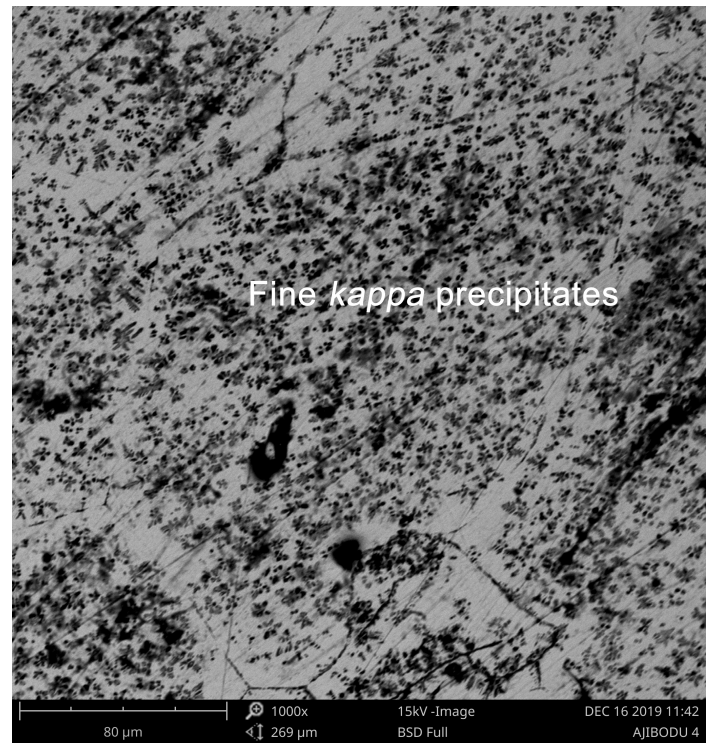

(a)

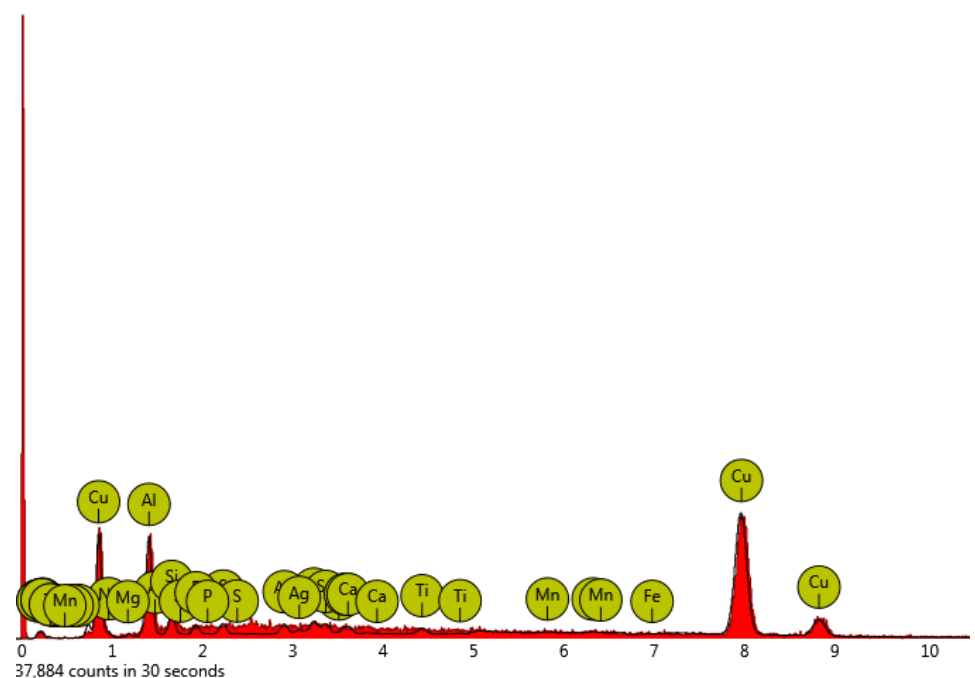

(b)

Figure 4: SEM/EDS of 6 wt.\% IMS addition 
$320^{\circ} \mathrm{C}$ for control and $6 \mathrm{wt} . \%$ IMS samples respectively. Heating the specimen from $30^{\circ} \mathrm{C}$ to $950^{\circ} \mathrm{C}$ at $10^{\circ} \mathrm{C}$ $/ \mathrm{min}$, the first derivative peak temperature (Tp) was obtained around $570^{\circ} \mathrm{C}$ and $600^{\circ} \mathrm{C}$ at $-3.75 \% / \mathrm{min}$ respectively for control and 6 wt.\% IMS samples. These points represent the greatest rate of change on the weight-loss curve for both samples. Above these temperatures, the samples began to degrade having suffered about $65 \%$ mass loss.

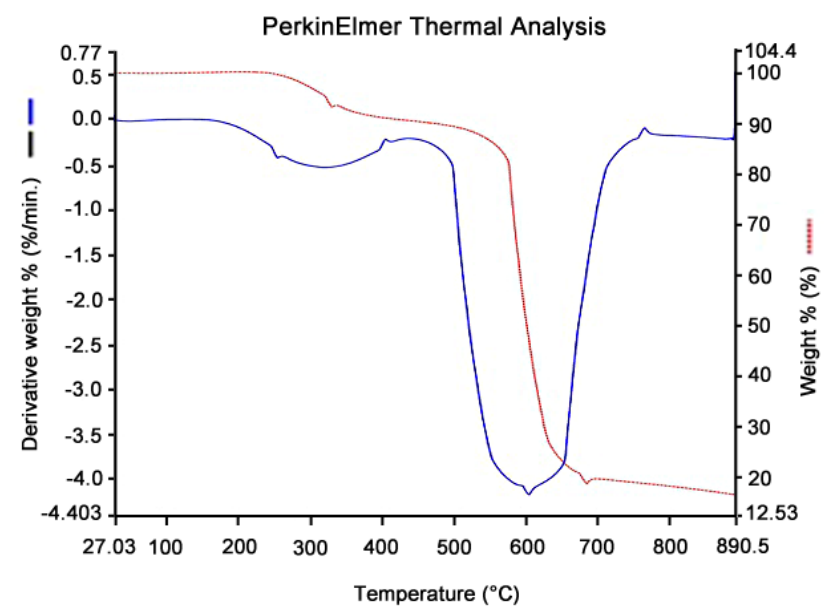

(a) 0 wt.\% IMS particle addition sample

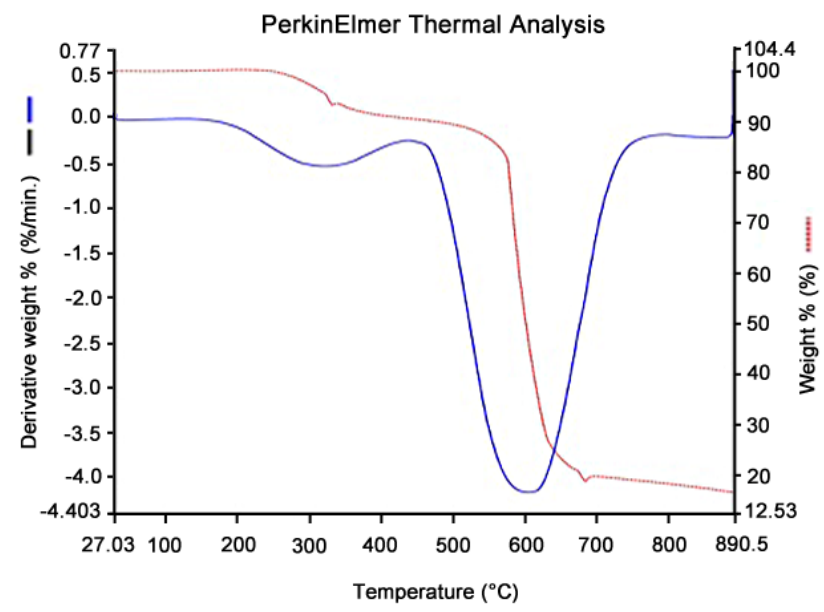

(b) 6 wt.\% IMS particle addition sample

Figure 5: TG/DTG curves

Furthermore, the 6 wt.\% IMS sample exhibited structural degradation at higher temperatures compared to the control sample indicating superior thermal characteristics of the $6 \mathrm{wt} . \%$ IMS sample. As reported by Andrea et al [3], this behaviour was attributed to the structure modifying influence of IMS particles. Finally the mass loss became stable at $670^{\circ} \mathrm{C}$. These results compared with $550^{\circ} \mathrm{C}-1650^{\circ} \mathrm{C}$ reported as the thermal characteristics of most materials employed in several smart devices such as pneumatic valve actuators and robots often deploy in nuclear plants [5, 9, 3].

\subsection{Tensile strength}

The different microstructural features induced in the alloys at varied materials formulation impact significantly the flow stress as shown in Figure 6. It was observed that tensile strength increased in response to increase in IMS particle addition to peak at $6 \mathrm{wt} . \%$ IMS. This trend corresponds to $93.8 \mathrm{MPa}$, being the least at 0 wt.\% but increased markedly to $118.7 \mathrm{MPa}$ on addition 2 wt.\% IMS particles. Further increase in strength occurred, 131.2 $\mathrm{MPa}$ at $4 \mathrm{wt} \%$ IMS reaching the optimum strength of $171.6 \mathrm{MPa}$ at $6 \mathrm{wt} . \%$ mixture.

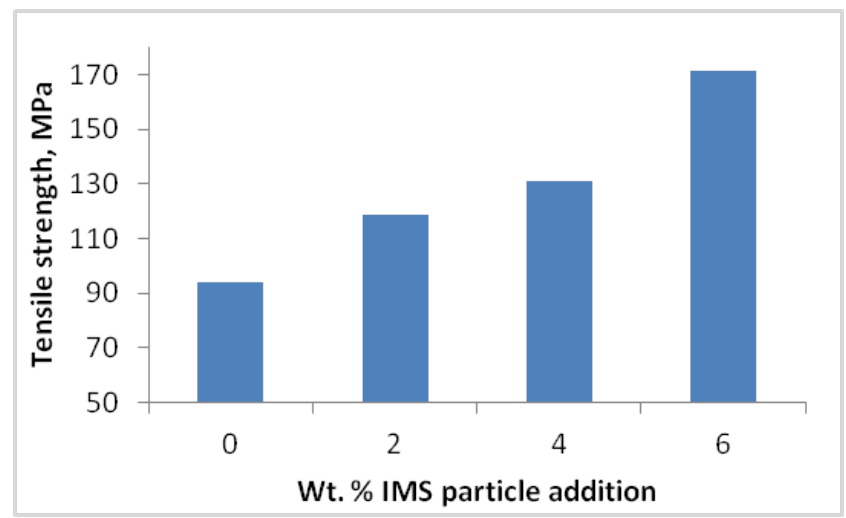

Figure 6: Tensile strength with varied IMS particle addition

The relatively low tensile strength (93.8 MPa) exhibited by the sample without IMS particle addition could be explained in relation to the absence of reinforcing particle phase. However, varied addition of IMS particles gave rise to solid solution strengthening of the structure owing to the formation of $\mathrm{AlCuFe}_{3}$ kappa pecipitates coupled with the presence of $\mathrm{AlFe}$, and $\mathrm{AlCu}$ intermetallics.

According to Adeyemi et al [1] and Qian et al [22], these hard precipitates and second phase particles compared to the other samples provided desirable impediment to dislocation motion within the matrices. Thus, their tensile strength was enhanced from 118.7 $\mathrm{MPa}$ to $171.6 \mathrm{MPa}$ at $6 \mathrm{wt} . \%$ IMS particle addition. The strength exhibited by the alloy is adjudged sufficient and comparable to the minimum $100 \mathrm{kPa}$ stress often encountered in operation by pneumatic valve actuators. 


\subsection{Impact energy}

The dynamic strength characteristics of the alloy at varied IMS addition is shown in Figure 7. Given that there is a correlation between the static and dynamic strength of a material, the amount of energy absorbed before fracture by samples cast from each formulation varied in tandem with the type of microstructure induced in the alloys. The highest impact energy of 27.8 Joules was obtained at $6 \mathrm{wt}$ \% IMS addition while the 0 wt.\% IMS sample exhibited the least impact energy value of 13.7 Joules. The superior impact toughness performance by the $6 \mathrm{wt} . \%$ IMS sample may have stemmed from the inducement of hard and coherent kappa $(\kappa)$ precipitates in the alpha $(\alpha)$ aluminium matrix.

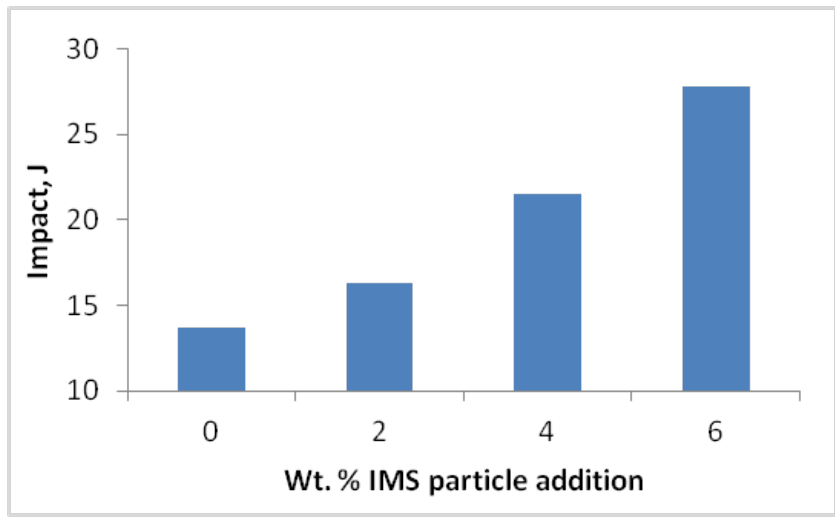

Figure 7: Impact energy with varied IMS particle addition

As explained by Kaiser and Kaiser [13], the kappa precipitates, being a stable and coherent secondary phase in the copper matrix provided sustained level of resistance to dislocation motion. For instance, the best toughness supporting microstructure consisting of fine kappa precipitates was induced in the 6 wt.\% IMS sample, hence its superior impact toughness performance. The range of impact energy which is 16.3-27.8 Joules demonstrated at 2-6 wt.\% IMS addition compared with 15-28 Joules obtained on addition of Zirconium ( $\mathrm{Zr}$ ) and Magnesium $(\mathrm{Mg})$ to commercial pure Aluminium (Al) [13].

\subsection{Hardness}

The alloy's ability to resist surface wear and indentation at varying IMS addition is illustrated in Figure 8. It is evident from the Figure 8 that hardness value increases in proportion to IMS particle addition. The control sample ( $0 \mathrm{wt} . \%$ IMS) exhibited the least hardness value of $307 \mathrm{HV}$ while the highest value of $386 \mathrm{HV}$ was demonstrated by the 6 wt.\% IMS sample. Overall, addition of 2-6 wt.\% IMS particle gave rise to hardness values in the range of 345-386 HV.

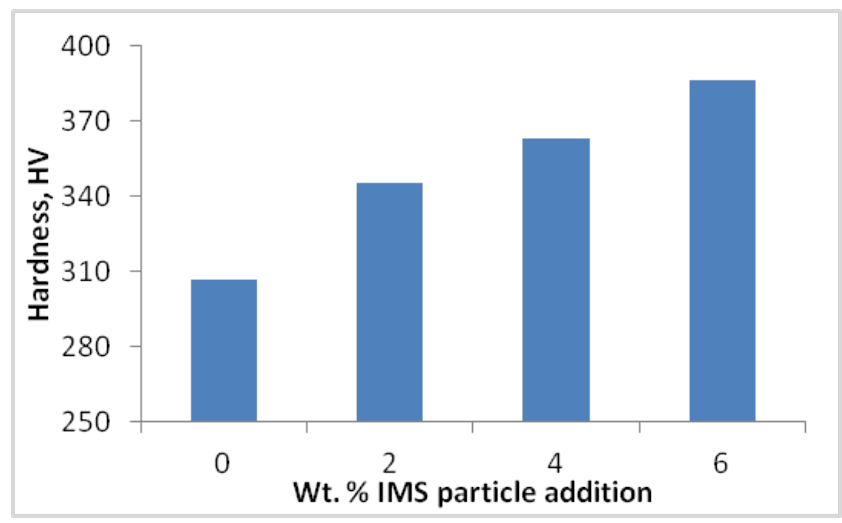

Figure 8: Alloy hardness with varied IMS addition

This level of performance presents significant improvement over the aluminium-bronze standard hardness range of 170-220 HV. The alloy hardness behaviour could be explained by the grain refining effect of $\mathrm{Fe}$ on the alloy [25]. Furthermore, the preponderance of hard and fine kappa precipitates induced within the matrices of micrographs shown in Figure 3d and Figure 4a. These resulted in grain boundaries increase which is usually a precursor to the development of hard structure with its characteristic high resistance to surface wear and indentation $[15,14]$.

\section{Conclusion}

The synthesis of aluminium-copper alloy for enhanced thermal and mechanical properties through the addition of IMS particles was investigated. The presence of IMS particles in the alloy significantly influenced the microstructure, which impacted the alloy's thermal and mechanical properties. From the results and their analyses, the following conclusions are drawn:

i) The 6 wt.\% IMS particle addition sample exhibited the best thermal and mechanical properties namely; tensile strength (171.6 MPa); impact energy (27. 8 Joules) and hardness (386 HV).

ii) The alloy attained thermal stability at $600^{\circ} \mathrm{C}$ owing to the inducement of fine and hard $\mathrm{AlCuFe}_{3}$ kappa precipitates consequent upon the addition of structure modifying IMS particles.

iii) Successful utilisation of IMS estimated at $22.3 \mathrm{~g}$ per sample portends a huge desirable value 
addition and a boost to the global quest for cleaner environment.

The outcomes of this study compared well with the conventional $\mathrm{Al}-\mathrm{Cu}$ and $\mathrm{Al}-\mathrm{Mg}$ alloys characteristics. Given the peak thermal stability of the developed $\mathrm{Al}-\mathrm{Cu}$-IMS alloy at $600^{\circ} \mathrm{C}$, the alloy is recommended for application as structural members in pneumatic actuators and robots intended to function below $600^{\circ} \mathrm{C}$. Further work is recommended to be carried out using IMS on nanoscale for possible application of the alloy in advance facilities such as nuclear and aerospace industries.

\section{References}

[1] G. J. Adeyemi, B. S. Oluwadare, and K. O. Olanipekun, "Investigation on the effect of addition of magnessium on the microstructure and mechanical properties of aluminum bronze," International Journal of Emerging Science Intervention, vol. 2, no. 11, pp. 1-13, 2013.

[2] S. Mehdi Aghaei, I. Torres, and I. Calizo, "Structural stability of functionalized silicene nanoribbons with normal, reconstructed, and hybrid edges," Journal of Nanomaterials, vol. 2016, pp. 1-8, 012016.

[3] A. Školáková, P. Novák, L. Mejzlíková, F. Průša, P. Salvetr, and D. Vojtěch, "Structure and mechanical properties of Al-Cu-Fe-X alloys with excellent thermal stability," Materials, vol. 10, pp. 69-97, 112017.

[4] W. D. Callister, Materials Science and Engineering: Principles of Fracture Mechanics, 7th ed. John Wiley \& Sons, Inc., 2007.

[5] W. Cao, H. H. Cudney, and R. Waser, "Smart materials and structures," Proceedings of the National Academy of Sciences, vol. 96, no. 15, pp. 8330-8331, 1999. [Online]. Available: https: //www.pnas.org/content/96/15/8330

[6] A. Rodríguez, A. Calleja, L. N. López de Lacalle, O. Pereira, H. González, G. Urbikain, and J. Laye, "Burnishing of FSW aluminum Al-Cu-Li components," Metals, vol. 9, no. 2, p. 260, 2019.

[7] I. Cenoz, "Metallography of aluminium bronze alloy as cast in permanent iron die," Metallurgical \& Materials Engineering, vol. 16, no. 2, pp. 115-122, 2010.

[8] E. Danilov, "Economical method of recycling metallurgical and mill scale by the sitfer technology in an arc steelmaking furnace," Metallurgist, vol. 47, no. 5, pp. 197-200, 2003.
[9] W.-G. Drossel, H. Kunze, A. Bucht, L. Weisheit, and K. Pagel, "Smart3-smart materials for smart applications," Procedia Cirp, vol. 36, pp. 211-216, 2015.

[10] M. Eissa, A. Ahmed, and M. El-Fawkhry, "Conversion of mill scale waste into valuable products via carbothermic reduction," Journal of Metallurgy, vol. 4, 2015.

[11] R. G. Guan and D. Tie, "A review on grain refinement of aluminum alloys: progresses, challenges and prospects," Acta Metallurgica Sinica (English Letters), vol. 30, no. 5, pp. 409-432, 2017.

[12] Y. Jia, L. Zhang, P. Li, X. Ma, L. Xu, S. Wu, Y. Jia, and G. Wang, "Microstructure and mechanical property of $\mathrm{Nb}-\mathrm{Ti}-\mathrm{V}-\mathrm{Zr}$ refractory medium-entropy alloys," Frontiers in Materials, vol. 7, p. 172, 2020.

[13] S. Kaiser and M. Kaiser, "Investigation of $\mathrm{Mg}$ and $\mathrm{Zr}$ addition on the mechanical properties of commercially pure Al," International Journal of Mechanical and Materials Engineering, vol. 13, no. 9, pp. 607-611, 2019.

[14] A. Lervik, S. Wenner, O. Lunder, C. D. Marioara, and R. Holmestad, "Grain boundary structures and their correlation with intergranular corrosion in an extruded Al-Mg-Si-Cu alloy," Materials Characterization, vol. 170, p. 110695, 2020.

[15] M. Moiz, "The influence of grain size on mechanical properties of Inconel 718," Linköping University, Sweden, 2013.

[16] A. L. Moore and L. Shi, "Emerging challenges and materials for thermal management of electronics," Materials today, vol. 17, no. 4, pp. 163-174, 2014.

[17] N. Mukhopadhyay, V. Uhlenwinkel, and V. Srivastava, "Synthesis and characterization of bulk Al-Cu-Fe based quasicrystals and composites by spray forming," Journal of Materials Engineering and Performance, vol. 24, no. 6, pp. 2172-2178, 2015.

[18] N. J. Nilsson, Quest for Artificial Intelligence: A History of Ideas and Achievements. Cambridge University Press, Stanford, UK, 2009.

[19] C. Nwaeju, J. Odo, and E. Nnuka, "Effect of niobium addition on the structure and mechanical properties of aluminium bronze $(\mathrm{Cu}-10 \% \mathrm{Al})$ alloy," International Journal of Research in Advanced Engineering and Technology, vol. 1, no. 2, pp. 70-75, 2015.

[20] C. Nwambu, I. Anyaeche, G. Onwubiko, and E. Nnuka, "Modification of the structure and mechanical properties of aluminum bronze (Cu-10with zirconium and titanium," International Journal of Scientific \& Engineering Research, vol. 8, no. 1, January 2017. 
[21] B. Pisarek, "The crystallization of the aluminium bronze with additions of Si, Cr, Mo and/or W," Archives of Materials Science and Engineering, vol. 28, no. 8, pp. 461-466, 2007.

[22] H. Qian, D. Zhu, C. Hu, and X. Jiang, "Effects of zr additive on microstructure, mechanical properties, and fractography of Al-Si alloy," Metals, vol. 8, no. 2, p. 124, 2018.

[23] S. Saberifar, F. Jafari, H. Kardi, M. A. Jafarzadeh, and S. A. Mousavi, "Recycling evaluation of mill scale in electric arc furnace," Journal of Advanced Materials and Processing, vol. 2, no. 3, pp. 73-78, 2014.
[24] D. Taylor and J. Knott, "Growth of fatigue cracks from casting defects in nickel-aluminium bronze," Metals Technology, vol. 9, no. 1, pp. 221-228, 1982.

[25] S. Yaro, V. Aigbodion, and O. Mohammed, "Effects of copper addition on the mechanical properties of Al-Si-Fe alloy," International Research Journal in Engineering \& Technology (IREJEST) FUTO, Owerri, Nigeria, vol. 3, no. 2, pp. 58-72, 2009.

[26] Y. Zhang, S. Balochian, P. Agarwal, V. Bhatnagar, and O. Houshia, "Artificial intelligence and its applications," Mathematical Problems in Engineering, vol. 2014, p. 10, 042014 